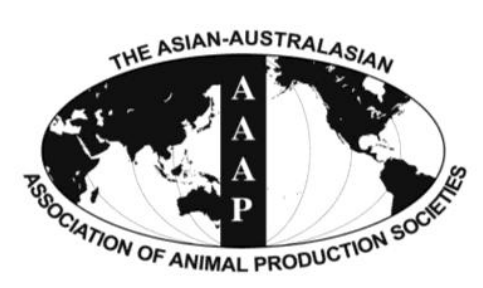

Open Access

Asian Australas. J. Anim. Sci.

Vol. 28, No. 4 : 502-510 April 2015

http://dx.doi.org/10.5713/ajas.14.0508

www.ajas.info

pISSN 101 1-2367 elSSN 1976-5517

\title{
Fermentation Characteristics and Lactic Acid Bacteria Succession of Total Mixed Ration Silages Formulated with Peach Pomace
}

\author{
Xiaodong Hu, Wei Hao, Huili Wang, Tingting Ning, Mingli Zheng, and Chuncheng $\mathrm{Xu}^{*}$ \\ College of Engineering, China Agricultural University, Beijing 100083, China
}

\begin{abstract}
The objective of this study was to assess the use of peach pomace in total mixed ration (TMR) silages and clarify the differences in aerobic stability between TMR and TMR silages caused by lactic acid bacteria (LAB). The TMR were prepared using peach pomace, alfalfa hay or Leymus chinensis hay, maize meal, soybean meal, cotton meal, limestone, a vitamin-mineral supplement, and salt in a ratio of 6.0:34.0:44.4:7.0:5.0:2.5:1.0:0.1 on a dry matter (DM) basis. Fermentation quality, microbial composition, and the predominant $\mathrm{LAB}$ were examined during ensiling and aerobic deterioration. The results indicated that the TMR silages with peach pomace were well fermented, with low $\mathrm{pH}$ and high lactic acid concentrations. The aerobic stability of TMR silages were significantly higher than that of TMR. Compared with TMR silages with alfalfa hay, TMR silage with Leymus chinensis hay was much more prone to deterioration. Although the dominant LAB were not identical in TMR, the same dominant species, Lactobacillus buchneri and Pediococcus acidilactici, were found in both types of TMR silages after $56 \mathrm{~d}$ of ensiling, and they may play an important role in the aerobic stability of TMR silages. (Key Words: Aerobic Stabilization, Lactic Acid Bacteria, Peach Pomace, Total Mixed Ration Silage)
\end{abstract}

\section{INTRODUCTION}

Peach juice is an internationally popular beverage because of its high nutritional value and health benefits, and with its consumption rising, approximately 700,000 tons of peach pomace is released annually by juice factories in China. Owing to its high moisture content $(94.1 \%)$ and a high water-soluble carbohydrates (WSC) content $(25.9 \%$ dry matter $[\mathrm{DM}])$, peach pomace is difficult to preserve at ambient temperature. It is easy for microorganisms to propagate if the pomace is not treated promptly, which can lead to great waste and potential environmental problems. Currently, most peach pomace is dumped in landfills, and a small amount is used for extraction of dietary fiber, pectin (Faravash and Ashtiani, 2008), and polyphenols (Adil et al., 2007). Peach pomace contains $7.36 \%$ crude protein (CP), $4.71 \%$ ether extract (EE) and $20.0 \%$ neutral detergent fiber (NDF) on a DM basis, and therefore could possibly be a source of nutrients for ruminants.

\footnotetext{
* Corresponding Author: Chuncheng Xu. Tel: +86-10-62736480, Fax: +86-10-62737997, E-mail: xucc@ cau.edu.cn

Submitted Jul. 10, 2014; Revised Sept. 16, 2014; Accepted Oct. 9, 2014
}

Many agricultural and industrial by-products have been used as feeds, including vegetable residues (Yang et al., 2010), rice straw (Gao et al., 2008), tomato and apple pomace (Abdollahzadeh et al., 2010), and green tea grounds (Wang et al., 2011), and they have shown good feed characteristics. Since high moisture can increase the risk of effluent production, mixing these by-products with other dry feeds to form a total mixed ration (TMR) would minimize the risk, stabilize microbial function, and improve energy and protein utilization in the rumen (Xu et al., 2007a, b). Furthermore, the efficient utilization of by-products also helps to develop new feed resources, thereby relieve the competition with humans for grain consumption.

Aerobic deterioration of silage has a severe impact on farm profitability. Spoiled silages not only reduce the palatability but also negatively affect livestock production performance. TMR silages have improved aerobic stability in comparison with silages (Nishino et al., 2004; Xu et al., 2010); however, the specific reason for this is still unknown. Nishino and Hattori (2007) isolated Lactobacillus buchneri as the predominant species of lactic acid bacteria (LAB) from aerobically stable silage, and they confirmed that inoculation of this bacterium can suppress aerobic

Copyright @ 2015 by Asian-Australasian Journal of Animal Sciences This is an open-access article distributed under the terms of the Creative Commons Attribution Non-Commercial License (http://creativecommons.org/licenses/by-nc/3.0/), which permits unrestricted non-commercial use, distribution, and reproduction in any medium, provided the original work is properly cited. 
deterioration of maize, Italian ryegrass, and festulolium silages. Results also suggested that L. buchneri might be associated with the stability of TMR silages, although the mechanism by which L. buchneri promotes aerobic stability in TMR silages has not been elucidated.

The purpose of this study was to evaluate the feasibility of TMR silages formulated with peach pomace and clarify the aerobic stability in TMR silages by comparing fermentation characteristics, aerobic stability, and dynamic changes in dominant LAB communities between TMR and TMR silages with peach pomace during ensiling and aerobic deterioration.

\section{MATERIALS AND METHODS}

\section{Preparation of total mixed ration silages}

The TMR were prepared using peach pomace, hay, maize meal, soybean meal, cotton meal, limestone, a vitamin-mineral supplement, and salt in a ratio of 6.0:34.0:44.4:7.0:5.0:2.5:1.0:0.1 on a DM basis (Table 1). Two common roughages, alfalfa hay and Leymus chinensis

Table 1. Ingredient, chemical and microbial composition of peach pomace and TMR

\begin{tabular}{lccc}
\hline Item & $\begin{array}{c}\text { Peach } \\
\text { pomace }\end{array}$ & ATMR & LTMR \\
\hline Ingredient (\% DM) & & & \\
Peach residue & & 6.0 & 6.0 \\
Leymus chinensis hay & & 0 & 34.0 \\
Alfalfa hay & 34.0 & 0 \\
Maize meal & & 44.4 & 44.4 \\
Soybean meal & & 7.0 & 7.0 \\
Cotton meal & & 5.0 & 5.0 \\
Limestone & & 2.5 & 2.5 \\
Vitamin-mineral supplement ${ }^{1}$ & 1.0 & 1.0 \\
Salt & & 0.1 & 0.1 \\
Chemical composition (\% DM) & & \\
DM (\%) & $5.9 \pm 0.32$ & $51.1 \pm 0.18$ & $51.9 \pm 0.26$ \\
OM & $95.1 \pm 0.13$ & $92.9 \pm 0.15$ & $93.1 \pm 0.23$ \\
CP & $7.36 \pm 0.10$ & $15.1 \pm 0.12$ & $12.3 \pm 0.08$ \\
EE & $4.71 \pm 0.36$ & $8.06 \pm 0.19$ & $7.78 \pm 0.21$ \\
NDF & $20.0 \pm 0.74$ & $29.7 \pm 0.34$ & $35.4 \pm 0.25$ \\
ADF & $11.9 \pm 0.60$ & $16.7 \pm 0.51$ & $17.8 \pm 0.39$ \\
WSC & $25.9 \pm 0.22$ & $17.7 \pm 0.36$ & $17.4 \pm 0.32$ \\
Microbial counts (log cfu/g fresh matter) & & \\
Lactic acid bacteria & $\mathrm{ND}$ & $4.20 \pm 0.12$ & $4.02 \pm 0.16$ \\
Yeasts & $\mathrm{ND}$ & $4.37 \pm 0.20$ & $4.25 \pm 0.12$ \\
\hline
\end{tabular}

TMR, total mixed ration; ATMR, total mixed ration with alfalfa hay; LTMR, total mixed ration with Leymus chinensis hay; DM, dry matter; $\mathrm{OM}$, organic matter; $\mathrm{CP}$, crude protein; $\mathrm{EE}$, ether extracts; NDF, neutral detergent fiber; ADF, acid detergent fiber; WSC, water soluble carbohydrate; ND, not detected; SD, standard deviation.

${ }^{1}$ Containing $1.2 \% \mathrm{Zn}, 1.0 \% \mathrm{Mn}, 0.5 \% \mathrm{Fe}, 0.2 \% \mathrm{Cu}$, and a minimum of $5,000 \mathrm{IU}$ vitamin $\mathrm{A} / \mathrm{g}$ and $600 \mathrm{IU}$ of vitamin $\mathrm{D} / \mathrm{g}$.

Data of chemical composition and microbial counts are presented as mean $\pm \mathrm{SD}$ of 3 replicates. hay, were used for the TMR with alfalfa hay (ATMR) and TMR with Leymus chinensis hay (LTMR) formulations in this study. The peach pomace was obtained from a local juice factory in Beijing and used within $12 \mathrm{~h}$ of production. The hays were cropped to a length of 1 to $2 \mathrm{~cm}$ prior to ensiling.

TMR were ensiled in plastic film bags (Hiryu KN type, $800 \times 1,500 \mathrm{~mm}$, Asahikasei, Tokyo, Japan). Approximately $2 \mathrm{~kg}$ of TMR were packed into each plastic film bag and the bags were degassed, sealed with a vacuum packing machine (BH950, Matsushita, Osaka, Japan), and stored at $18^{\circ} \mathrm{C}$ to $23^{\circ} \mathrm{C}$. The experiment was carried out according to a completely randomized design, and triplicate bags were opened after 1, 3, 7, 14, 28, and $56 \mathrm{~d}$ of ensiling.

\section{Evaluation of aerobic stability}

The TMR were subjected to an aerobic stability experiment right after preparation. Approximately $2 \mathrm{~kg}$ of TMR were placed in a $10 \mathrm{~L}$ polyethylene barrel without compaction. The temperatures of ambience and the materials were automatically monitored at $1 \mathrm{~h}$ intervals using a thermocouple wire connected to a data logger (DT85 Series2, dataTaker, Melbourne, Australia). Aerobic deterioration was considered to have occurred if the difference between the ambient temperature and the temperature of the material reached $2^{\circ} \mathrm{C}$. The aerobic stability test for the TMR was conducted for $7 \mathrm{~d}$, and subsamples were collected after $0,6,12,24,48,72,120$, and $168 \mathrm{~h}$ of air exposure. To determine the aerobic stability of the TMR silages, bags were opened after 28 and $56 \mathrm{~d}$ of ensilage and the entire contents were manually mixed. Half of the contents were placed loosely in a $10 \mathrm{~L}$ barrel and monitored as described above for unfermented TMR. Temperatures were recorded for $14 \mathrm{~d}$ and subsamples were collected at $0,6,12,24,48,72,120,168,216,264$, and 336 h. The aerobic stability experiments were carried out in a room maintained at $27^{\circ} \mathrm{C}$ to $31^{\circ} \mathrm{C}$. Triplicate samples were taken during ensiling and the aerobic stability test for evaluation of chemical composition, fermentation quality, and microbial composition.

\section{Chemical analysis}

Samples were dried in a fan-forced oven at $60^{\circ} \mathrm{C}$ for 48 $\mathrm{h}$ and ground with a Wiley mill to pass a $1 \mathrm{~mm}$ screen. DM, $\mathrm{CP}$, and EE were analyzed according to methods 934.01, 976.05, and 920.39, respectively, of the AOAC (1990). NDF and acid detergent fiber were analyzed as described by Van Soest et al. (1991). WSC content was determined using the method of Wang et al. (2011).

Fermentation qualities were determined by measuring fermentation products in cold-water extracts of the TMR. Wet samples $(10 \mathrm{~g})$ were homogenized with $90 \mathrm{~mL}$ of sterilized distilled water. The $\mathrm{pH}$ was measured with a 
glass-electrode $\mathrm{pH}$ meter (S20, Mettler Toledo, Greifensee, Switzerland). After centrifugation $\left(18,000 \times g, 15 \mathrm{~min}, 4^{\circ} \mathrm{C}\right)$, the supernatant was analyzed for ammonia nitrogen $\left(\mathrm{NH}_{3^{-}}\right.$ N) by the method of Wang et al. (2011). The TMR extracts were centrifuged at $12,000 \times \mathrm{g}$ for $5 \mathrm{~min}$. The supernatants were passed through a $0.45 \mu \mathrm{m}$ filter under pressure and then injected into a liquid chromatography system to determine organic acid concentrations. The analytical conditions were as follows: column, Hitachi GL C-610H; oven temperature $70^{\circ} \mathrm{C}$; mobile phase, $0.2 \% \mathrm{H}_{3} \mathrm{PO}_{4}, 1.0$ $\mathrm{mL} / \mathrm{min}$; detector, L-7420 SUV-Vis.

\section{Microbiological analysis}

The numbers of LAB and yeast were counted using the plate count method (Xu et al., 2008). Colonies were counted from the plates at appropriate dilutions and the numbers were expressed as colony-forming unit (cfu) per gram on fresh matter (FM) basis. The predominant LAB was considered as the one that appears on plates at the highest dilution. According to the colonial morphology, each kind of LAB colony was purified by repeated streaking on de Man-Rogosa and Sharp agar until only colonies of the same morphology formed on each plate. DNA of purified LAB was extracted by the hexadecyl trimethyl ammonium bromide method (Kim et al., 1990). In order to identify the species of $\mathrm{LAB}$, polymerase chain reaction (PCR) was carried out to amplify the $16 \mathrm{~S}$ rRNA gene with the forward primer $27 \mathrm{f}\left(5^{\prime}\right.$ AGAGTTTGATCCTGGCTCAG-3') and the reverse primer 1492r (5'-GGTTACCTTGTTACGACTT-3'). The PCR mixture contained $2.5 \mu \mathrm{L}$ of $10 \times \mathrm{PCR}$ buffer (with $\mathrm{Mg}^{2+}$ ), 2 $\mu \mathrm{L}$ of dNTPs $(2 \mathrm{mM}), 0.4 \mu \mathrm{L}$ of Taq polymerase $(5 \mathrm{U} / \mu \mathrm{L}), 2$ $\mu \mathrm{L}$ of DNA template, and $0.2 \mu \mathrm{L}$ of each primer $(10 \mathrm{mM})$, and double-distilled water was added to obtain a final volume of $25 \mu \mathrm{L}$. The PCR program comprised an initial denaturation at $95^{\circ} \mathrm{C}$ for $4 \mathrm{~min} ; 35$ cycles of denaturation at $94^{\circ} \mathrm{C}$ for $1 \mathrm{~min}$, annealing at $50^{\circ} \mathrm{C}$ for $1 \min 20 \mathrm{~s}$, and extension at $72^{\circ} \mathrm{C}$ for $1 \mathrm{~min} 30 \mathrm{~s}$; and a final extension at $72^{\circ} \mathrm{C}$ for $8 \mathrm{~min}$. The reaction was conducted in a PCR thermal cycler (TP-600, Takara Bio Inc., Shiga, Japan). Sequencing was carried out by Shanghai Sunny Biotechnology Co., Ltd.

\section{Statistical analysis}

The chemical composition, fermentation quality, microbial composition and hours of aerobic stability were subjected to one-way analysis of variance using the general linear model procedure of the SAS software package (SAS, 2004) to evaluate the statistical significance of the differences between TMR and TMR silage, setting fermentation time and experimental data as the main factor and random factor, respectively. Tukey's test was used to differentiate between means and significance was declared at $\mathrm{p}<0.05$.

\section{RESULTS}

\section{Chemical and microbial composition of materials}

The peach pomace had a low DM content and a high WSC content. No LAB or yeasts were detected in the peach pomace. The two TMR had similar DM and WSC contents. Mixing with other dry feed reduced the moisture content and WSC content of peach pomace. In addition, the CP content increased to $15.1 \%$ and $12.3 \%$ DM in ATMR and LTMR, respectively, improving the utilization of peach pomace as a feed resource. The populations of LAB and yeasts were approximately $10^{4} \mathrm{cfu} / \mathrm{g}$ FM in both TMR (Table 1).

\section{Chemical and microbial composition and fermentation quality of total mixed ration silages}

Irrespective of the type of roughage, the DM contents of TMR silages reduced by less than $2.0 \%$ compared with the corresponding unfermented TMR (Table 2). DM contents decreased significantly $(p<0.05)$ between 3 and $7 d$ and between 1 and $7 \mathrm{~d}$ in ATMR and LTMR, respectively. After 28 and $56 \mathrm{~d}$ of ensiling, the WSC contents decreased to below $9.50 \% \mathrm{DM}$ in both TMR silages. There was a rapid decline $(\mathrm{p}<0.05)$ in WSC content during the first $7 \mathrm{~d}$ in ATMR silage and then followed by a slow decline $(p>0.05)$ until 56 d. In LTMR silage, WSC content decreased significantly $(p<0.05)$ throughout the entire ensiling period. The CP contents increased $(\mathrm{p}<0.05)$ in both TMR silages compared with the corresponding TMR after $56 \mathrm{~d}$ of ensiling, but the increase was small.

Both TMR silages were well preserved after 28 and $56 \mathrm{~d}$ of ensiling, as indicated by low $\mathrm{pH}$ values and $\mathrm{NH}_{3}-\mathrm{N}$ concentrations and high lactic acid concentrations. The $\mathrm{pH}$ of ATMR silage and LTMR silage stabilized after 14 and 28 $\mathrm{d}$ of ensiling, respectively. Concentrations of $\mathrm{NH}_{3}-\mathrm{N}$ reached the maximum at $14 \mathrm{~d}$ in ATMR silage and LTMR silage, respectively; they decreased thereafter, but the change was not significant $(p>0.05)$. Lactic acid concentration increased rapidly during the first $14 \mathrm{~d}$ in ATMR silage and peaked at $7.11 \% \mathrm{DM}$ after $56 \mathrm{~d}$ of ensiling. In LTMR silage, lactic acid concentration increased during the first $28 \mathrm{~d}$ and then decreased, but there was no significant difference ( $p>0.05$ ) between 28 and $56 \mathrm{~d}$. Acetic acid concentration increased throughout the ensiling period in ATMR silage but reached a maximum at $3 \mathrm{~d}$ in LTMR silage.

The LAB populations increased rapidly after the start of ensiling and reached a maximum at $3 \mathrm{~d}$ in both TMR silages. After $56 \mathrm{~d}$ of storage, LAB populations were $10^{6} \mathrm{cfu} / \mathrm{g}$ FM. There were no large changes in the number of yeast between TMR and TMR silages, and populations were 
Table 2. Changes in chemical composition, fermentation quality and microbial composition during ensiling of ATMR silage and LTMR silage

\begin{tabular}{|c|c|c|c|c|c|c|c|}
\hline \multirow{2}{*}{ Item } & & \multicolumn{6}{|c|}{ Days of ensiling } \\
\hline & & 1 & 3 & 7 & 14 & 28 & 56 \\
\hline \multicolumn{8}{|c|}{ Chemical composition (\% DM) } \\
\hline \multirow[t]{2}{*}{$\mathrm{DM}(\%)$} & ATMR & $50.7^{\mathrm{a}} \pm 0.67$ & $50.6^{\mathrm{a}} \pm 0.37$ & $49.4^{\mathrm{b}} \pm 0.16$ & $49.3^{b} \pm 0.52$ & $49.0^{\mathrm{b}} \pm 1.07$ & $48.8^{\mathrm{b}} \pm 0.13$ \\
\hline & LTMR & $51.1^{\mathrm{a}} \pm 0.85$ & $50.2^{\mathrm{b}} \pm 0.59$ & $49.5^{\mathrm{bc}} \pm 0.05$ & $49.3^{c} \pm 0.07$ & $49.5^{\mathrm{bc}} \pm 0.19$ & $49.1^{c} \pm 0.09$ \\
\hline \multirow[t]{2}{*}{$\mathrm{CP}$} & ATMR & $15.2^{\mathrm{b}} \pm 0.14$ & $15.2^{\mathrm{b}} \pm 0.09$ & $15.7^{\mathrm{a}} \pm 0.12$ & $15.6^{\mathrm{a}} \pm 0.12$ & $15.7^{\mathrm{a}} \pm 0.32$ & $15.8^{\mathrm{a}} \pm 0.31$ \\
\hline & LTMR & $12.6^{\mathrm{b}} \pm 0.23$ & $13.4^{\mathrm{a}} \pm 0.10$ & $13.4^{\mathrm{a}} \pm 0.69$ & $13.4^{\mathrm{a}} \pm 0.36$ & $13.4^{\mathrm{a}} \pm 0.16$ & $13.4^{\mathrm{a}} \pm 0.53$ \\
\hline \multirow[t]{2}{*}{ WSC } & ATMR & $15.3^{\mathrm{a}} \pm 1.43$ & $12.9^{\mathrm{b}} \pm 1.25$ & $10.5^{\mathrm{c}} \pm 1.29$ & $9.12^{\mathrm{c}} \pm 0.32$ & $9.02^{\mathrm{c}} \pm 0.06$ & $8.90^{c} \pm 0.00$ \\
\hline & LTMR & $16.9^{\mathrm{a}} \pm 0.88$ & $15.7^{\mathrm{b}} \pm 0.45$ & $11.8^{\mathrm{c}} \pm 0.54$ & $9.32^{\mathrm{d}} \pm 0.16$ & $9.44^{\mathrm{d}} \pm 0.32$ & $8.63^{\mathrm{e}} \pm 0.03$ \\
\hline \multirow[t]{2}{*}{ NDF } & ATMR & $30.1 \pm 0.85$ & $31.0 \pm 0.86$ & $30.0 \pm 2.97$ & $29.5 \pm 1.14$ & $30.2 \pm 1.12$ & $29.8 \pm 1.89$ \\
\hline & LTMR & $34.5 \pm 2.06$ & $35.7 \pm 0.22$ & $35.2 \pm 0.64$ & $35.5 \pm 0.22$ & $34.9 \pm 0.32$ & $34.7 \pm 0.16$ \\
\hline \multirow[t]{2}{*}{$\mathrm{ADF}$} & ATMR & $17.7 \pm 1.33$ & $17.8 \pm 0.57$ & $17.3 \pm 0.88$ & $18.4 \pm 0.87$ & $18.3 \pm 1.63$ & $18.4 \pm 1.56$ \\
\hline & LTMR & $17.2 \pm 0.19$ & $18.0 \pm 1.23$ & $17.4 \pm 0.70$ & $17.7 \pm 0.59$ & $17.8 \pm 0.33$ & $17.9 \pm 0.32$ \\
\hline \multicolumn{8}{|l|}{ Fermentation quality } \\
\hline \multirow[t]{2}{*}{$\mathrm{pH}$} & ATMR & $5.25^{\mathrm{a}} \pm 0.30$ & $4.61^{\mathrm{b}} \pm 0.05$ & $4.63^{b} \pm 0.09$ & $4.39^{c} \pm 0.04$ & $4.29^{c} \pm 0.00$ & $4.29^{c} \pm 0.01$ \\
\hline & LTMR & $4.91^{\mathrm{a}} \pm 0.17$ & $4.81^{\mathrm{a}} \pm 0.04$ & $4.52^{\mathrm{b}} \pm 0.12$ & $4.56^{\mathrm{b}} \pm 0.13$ & $4.36^{\mathrm{bc}} \pm 0.25$ & $4.24^{c} \pm 0.02$ \\
\hline \multirow[t]{2}{*}{ Lactic acid (\% DM) } & ATMR & $1.43^{\mathrm{e}} \pm 0.06$ & $3.77^{\mathrm{d}} \pm 0.12$ & $5.24^{\mathrm{c}} \pm 0.24$ & $6.53^{\mathrm{b}} \pm 0.08$ & $6.54^{\mathrm{b}} \pm 0.08$ & $7.11^{\mathrm{a}} \pm 0.10$ \\
\hline & LTMR & $2.40^{\mathrm{e}} \pm 0.07$ & $2.64^{\mathrm{d}} \pm 0.10$ & $5.48^{\mathrm{c}} \pm 0.16$ & $5.94^{\mathrm{b}} \pm 0.14$ & $6.24^{\mathrm{a}} \pm 0.17$ & $6.21^{\mathrm{a}} \pm 0.04$ \\
\hline \multirow[t]{2}{*}{ Acetic acid (\% DM) } & ATMR & $0.60^{\mathrm{d}} \pm 0.08$ & $0.83^{c} \pm 0.03$ & $1.07^{\mathrm{b}} \pm 0.06$ & $1.16^{\mathrm{b}} \pm 0.06$ & $1.18^{\mathrm{b}} \pm 0.08$ & $1.38^{\mathrm{a}} \pm 0.07$ \\
\hline & LTMR & $0.84^{\mathrm{b}} \pm 0.10$ & $0.88^{\mathrm{b}} \pm 0.08$ & $1.09^{\mathrm{a}} \pm 0.11$ & $0.96^{\mathrm{ab}} \pm 0.05$ & $0.96^{\mathrm{ab}} \pm 0.02$ & $0.90^{\mathrm{b}} \pm 0.10$ \\
\hline \multirow[t]{2}{*}{$\mathrm{NH}_{3}-\mathrm{N}(\% \mathrm{TN})$} & ATMR & $1.01^{\mathrm{d}} \pm 0.16$ & $1.53^{\mathrm{c}} \pm 0.08$ & $2.13^{\mathrm{b}} \pm 0.19$ & $3.39^{\mathrm{a}} \pm 0.14$ & $3.18^{\mathrm{a}} \pm 0.11$ & $3.21^{\mathrm{a}} \pm 0.14$ \\
\hline & LTMR & $2.32^{\mathrm{c}} \pm 0.16$ & $2.62^{c} \pm 0.34$ & $3.80^{\mathrm{b}} \pm 0.34$ & $4.69^{\mathrm{a}} \pm 0.26$ & $4.49^{\mathrm{a}} \pm 0.40$ & $4.39^{\mathrm{a}} \pm 0.00$ \\
\hline \multicolumn{8}{|c|}{ Microbial counts (log cfu/g fresh matter) } \\
\hline \multirow[t]{2}{*}{ Lactic acid bacteria } & ATMR & $8.64^{\mathrm{ab}} \pm 0.40$ & $9.05^{\mathrm{a}} \pm 0.34$ & $8.89^{\mathrm{ab}} \pm 0.11$ & $8.55^{\mathrm{b}} \pm 0.21$ & $7.25^{\mathrm{c}} \pm 0.15$ & $6.74^{\mathrm{d}} \pm 0.23$ \\
\hline & LTMR & $6.94^{c} \pm 0.21$ & $8.80^{\mathrm{a}} \pm 0.30$ & $8.45^{\mathrm{a}} \pm 0.20$ & $8.67^{\mathrm{a}} \pm 0.22$ & $7.94^{\mathrm{b}} \pm 0.16$ & $6.63^{\mathrm{c}} \pm 0.33$ \\
\hline \multirow[t]{2}{*}{ Yeasts } & ATMR & $5.72^{\mathrm{b}} \pm 0.28$ & $6.73^{\mathrm{a}} \pm 0.18$ & $6.86^{\mathrm{a}} \pm 0.30$ & $5.73^{\mathrm{b}} \pm 0.27$ & $4.56^{\mathrm{c}} \pm 0.18$ & $4.21^{\mathrm{c}} \pm 0.21$ \\
\hline & LTMR & $5.88^{\mathrm{a}} \pm 0.29$ & $6.75^{\mathrm{a}} \pm 0.32$ & $5.98^{\mathrm{a}} \pm 0.14$ & $5.83^{\mathrm{a}} \pm 0.26$ & $4.86^{\mathrm{c}} \pm 0.14$ & $4.27^{\mathrm{d}} \pm 0.10$ \\
\hline
\end{tabular}

ATMR, total mixed ration with alfalfa hay; LTMR, total mixed ration with Leymus chinensis hay; DM, dry matter; CP, crude protein; WSC, water soluble carbohydrate; NDF, neutral detergent fiber; $\mathrm{ADF}$, acid detergent fiber; $\mathrm{NH}_{3}-\mathrm{N}$, ammonia-N; SD, standard deviation .

Data are presented as mean \pm SD of 3 replicates. Within a row, means without a common superscript letter differ $(\mathrm{p}<0.05)$.

above $10^{4} \mathrm{cfu} / \mathrm{g}$ FM after 28 and $56 \mathrm{~d}$ of ensiling. These large populations were probably due to the high content of available carbohydrates in peach pomace.

\section{Aerobic stability of total mixed ration and total mixed ration silages}

Regardless of hay species, both TMR and TMR silages increased in temperature during the aerobic stability test. In both TMR, the temperature increased and aerobic deterioration occurred at the same time. Compared with TMR, the aerobic stability of TMR silage significantly increased $(\mathrm{p}<0.05)$ after fermentation. After $28 \mathrm{~d}$ of ensiling, the time of increase in temperature extended to 120 and 72 $\mathrm{h}$, and aerobic deterioration was observed at 148 and $90 \mathrm{~h}$ for ATMR silage and LTMR silage, respectively. When ensiling was prolonged to $56 \mathrm{~d}$, the temperature of ATMR silages increased at $144 \mathrm{~h}$ and aerobic deterioration occurred at $155 \mathrm{~h}$, while the temperature of LTMR silage began to increase at $72 \mathrm{~h}$ and aerobic deterioration occurred at $90 \mathrm{~h}$ (Figure 1).
Microbial composition, $\mathrm{pH}$, and organic acids of total mixed ration and total mixed ration silages during aerobic deterioration

In both $\mathrm{TMR}$, the $\mathrm{LAB}$ populations increased rapidly during the first $24 \mathrm{~h}$ of the aerobic stability test and then followed by a stable period until $120 \mathrm{~h}$, finally, they had a declining tendency. A different pattern was observed in TMR silages: the LAB populations showed a slight downward trend during the first $120 \mathrm{~h}$ in ATMR silage and $72 \mathrm{~h}$ in LTMR silage, regardless of ensiling time, and then increased gradually until they were stable. Yeast populations increased during the first 48 and $72 \mathrm{~h}$ in ATMR and LTMR, respectively, and then leveled off. After 28 and $56 \mathrm{~d}$ of ensiling, yeast populations decreased slightly, then rose slowly and began rapidly to increase at about $72 \mathrm{~h}$, and finally stabilized or declined slightly.

The changes in $\mathrm{pH}$ showed good agreement with the changes in organic acids, LAB populations, and time to aerobic deterioration. The $\mathrm{pH}$ slowly decreased and reached a minimum at $24 \mathrm{~h}$ in both TMR. In 28-d and 56-d ATMR silages, $\mathrm{pH}$ remained stable until 120 and $216 \mathrm{~h}$, 


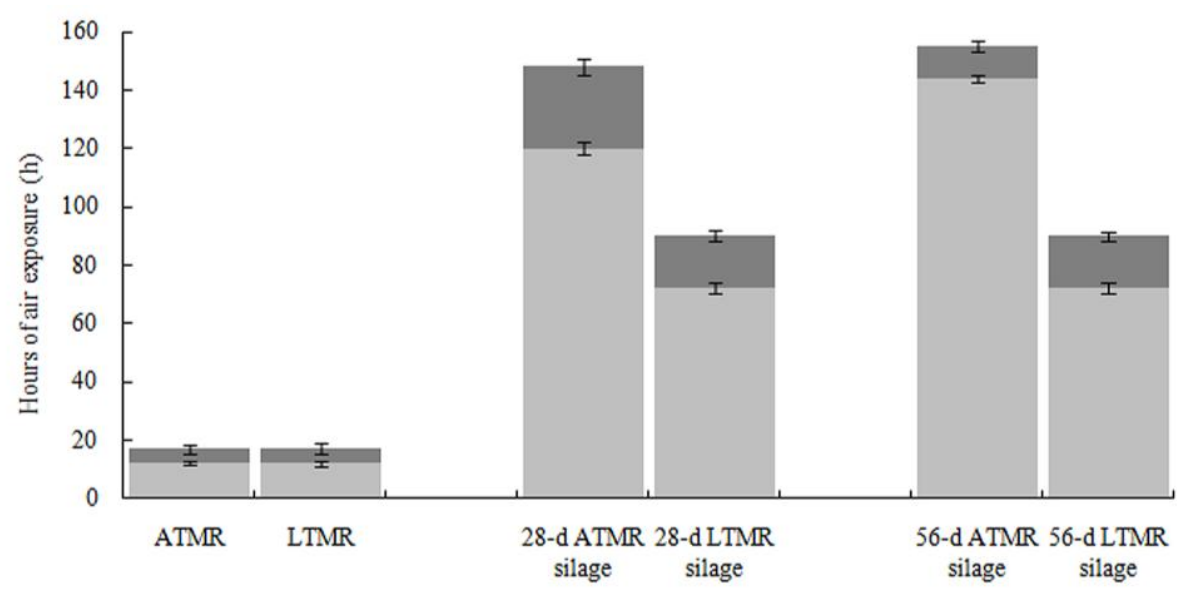

Figure 1. The time of increases in temperature and aerobic deterioration of TMR and TMR silages. The time between silo opening to increases in temperature and between increases in temperature to aerobic deterioration were marked by $\square$, $\square$ respectively. TMR, total mixed ration.

respectively. In LTMR silage, $\mathrm{pH}$ began to rise rapidly at $120 \mathrm{~h}$ after a stable period. With the start of aerobic deterioration, the $\mathrm{pH}$ increased rapidly in both TMR and TMR silages.

For both TMR, the lactic acid concentrations initially increased and then declined during air exposure, peak concentrations were observed at $24 \mathrm{~h}$ in ATMR and $12 \mathrm{~h}$ in LTMR. Similar trends were observed for acetic acid concentrations, and peak values were observed after $24 \mathrm{~h}$ of air exposure. For the TMR silages, lactic acid concentrations were initially stable or declined slightly and then decreased significantly. The concentration of acetic acid gradually decreased in ATMR silage, while it peaked at $24 \mathrm{~h}$ and then decreased in LTMR silage (Figures 2 and 3).

\section{Changes in the lactic acid bacteria community during} fermentation and aerobic deterioration

During ensiling and aerobic deterioration, different stages were identified according to significant changes in the predominant LAB. Pediococcus pentosaceus, Pediococcus acidilactici, Lactobacillus brevis, Weissella paramesenteroides, Lactobacillus buchneri, and Weissella cibaria were isolated from TMR, irrespective of the type of roughage. Two additional LAB species, namely Lactobacillus plantarum and Enterococcus avium, were detected when TMR was formulated with alfalfa hay. Although the predominant LAB species were not identical in the two TMRs, after $56 \mathrm{~d}$ of ensiling, the two TMR silages had the same predominant species: L. buchneri and P. acidilactici (Table 3).

During aerobic deterioration, there were no marked changes in the predominant LAB in TMR. Although $W$. paramesenteroides and $P$. acidilactici lost their dominant position in the later stage of aerobic deterioration in ATMR and LTMR, respectively, $P$. acidilactici remained predominant nearly throughout the period of air exposure in both TMR silages. In 28-d and 56-d silages, L. buchneri became co-dominant in the later stage of deterioration, regardless of whether it had occurred in the early stage (Table 4).

\section{DISCUSSION}

Many agricultural and industrial by-products with high moisture contents, such as coffee and tea grounds (Xu et al., 2007a, b; 2010), dry tofu cake, and apple pomace (Cao et al., 2009), have been ensiled with dry feeds as a TMR to avoid the risk of effluent production. The results demonstrated that these by-products can be used as ingredients of TMR without affecting palatability and nutritional value and that they are potential energy sources in ruminant diets. In this study, we prepared TMR with peach pomace and ensiled them to produce TMR silages. The TMR silages were well fermented, with low $\mathrm{pH}$ values and high lactic acid concentrations. Furthermore, they kept the color of the raw material and maintained the fragrance of fresh fruit. These results show that peach pomace can be effectively utilized as a component of TMR.

Silages with high concentrations of lactic acid or WSC are prone to deterioration in the presence of air (McDonald et al., 1991). Recent studies have shown that lactateassimilating yeasts are generally the main initiators of the aerobic spoilage of silages; under aerobic conditions, they utilize lactic acid, causing an increase in silage temperature and $\mathrm{pH}$ (Pahlow et al., 2003). With the increase of $\mathrm{pH}$, bacilli and other aerobic bacteria start growing quickly, increasing the temperature further. Finally, molds complete the deterioration of the silage (Muck, 2013). In this study, yeasts were not suppressed effectively even when ensiling was prolonged to $56 \mathrm{~d}$. There was no significant difference 


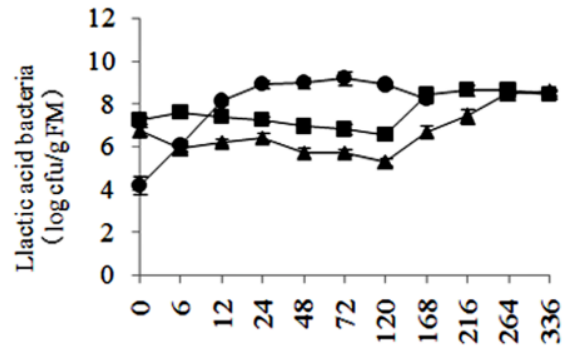

Hours of air exposure ( $h$ )

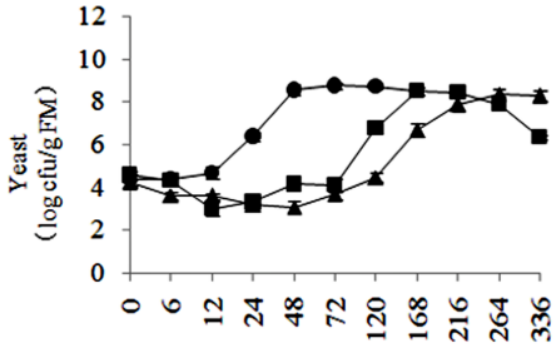

Hours of air exposure（h）
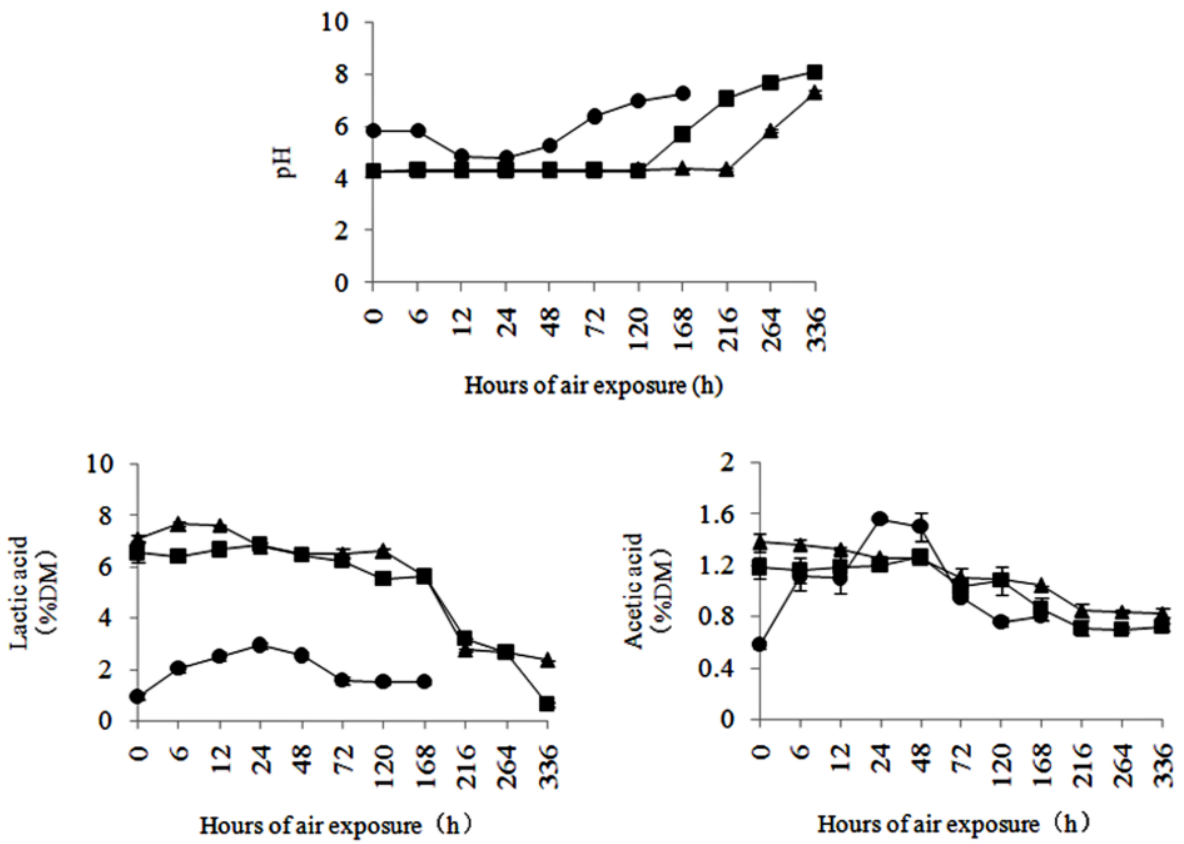

Figure 2. Microbial composition, $\mathrm{pH}$ and organic acids of ATMR and ATMR silages in the processing of aerobic deterioration. TMR were marked by $\bullet$, TMR silages after $28 \mathrm{~d}$ of ensiling were marked by $\boldsymbol{\bullet}$, and TMR silages after $56 \mathrm{~d}$ of ensiling were marked by $\boldsymbol{\Delta}$. ATMR, total mixed ration with alfalfa hay; TMR, total mixed ration.

( $p>0.05)$ in the number of yeast between TMR and TMR silages; in all cases, the yeast population was above $10^{4}$ $\mathrm{cfu} / \mathrm{g}$ FM. These large populations were probably due to the high WSC content of peach pomace. Our results contrast with earlier reports in which the number of yeast was $10^{2}$ cfu/g FM or less in the later stage of ensiling (Nishino et al., 2004; Nishino and Hattori, 2007; Wang and Nishino, 2008). Despite the large yeast populations in this study, the TMR silages had higher $(\mathrm{p}<0.05)$ aerobic stability than the TMR. Although the number of yeast was not reduced by ensiling, the time of beginning to proliferate during aerobic stability test was obviously extended. This shows that the yeast populations at silo opening had less effect on aerobic stability, and yeast species may play a more important role in this stability.

For each TMR formulation, there was no significant difference $(\mathrm{p}>0.05)$ in $\mathrm{pH}$ between $28-\mathrm{d}$ and 56-d silages. On the other hand, the concentrations of lactic and acetic acids were higher $(\mathrm{p}<0.05)$ in 56-d ATMR silage than in 28- d ATMR silage, while no significant differences $(\mathrm{p}>0.05)$ were observed between 28 and $56 \mathrm{~d}$ for LTMR silage. Since there was a difference in aerobic stability between 28 -d and 56-d ATMR silages, there appears to be a relationship between undissociated acids and aerobic stability. Undissociated acids are known to exhibit antifungal activity during ensiling and upon exposure to air, but in this study, the increased acetic acid concentration did not significantly reduce the number of yeast in 28-d and 56-d ATMR silage.

Previous studies have suggested that the high stability of TMR silages could be attributed to the activity of $L$. buchneri; these bacteria always appeared in long-stored TMR silages, but it is unknown whether they were present in the ensiled materials or appeared during fermentation (Wang and Nishino, 2009). In this study, L. buchneri was isolated from TMR before ensiling, and although it was present in relatively small numbers, it multiplied rapidly after $28 \mathrm{~d}$ of ensiling. Although L. buchneri was not the predominant species in 28-d TMR silages, it grew rapidly 


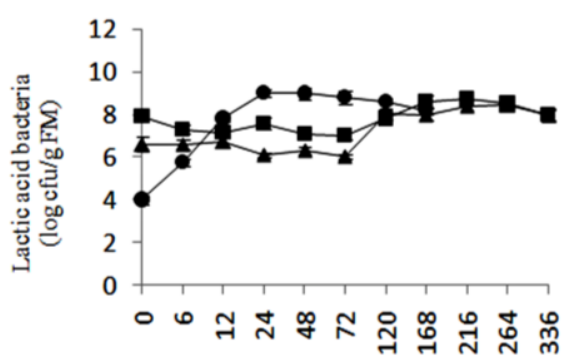

Hours of air exposure (h)

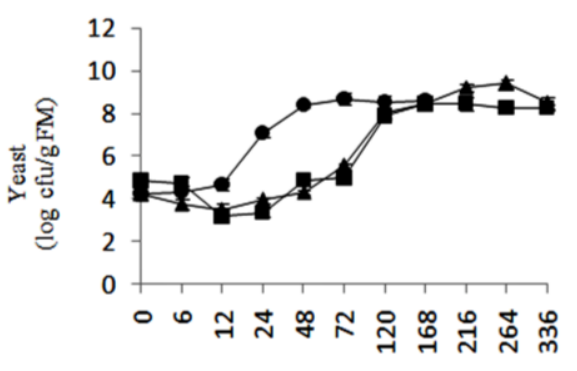

Hours of air exposure $(\mathrm{h})$
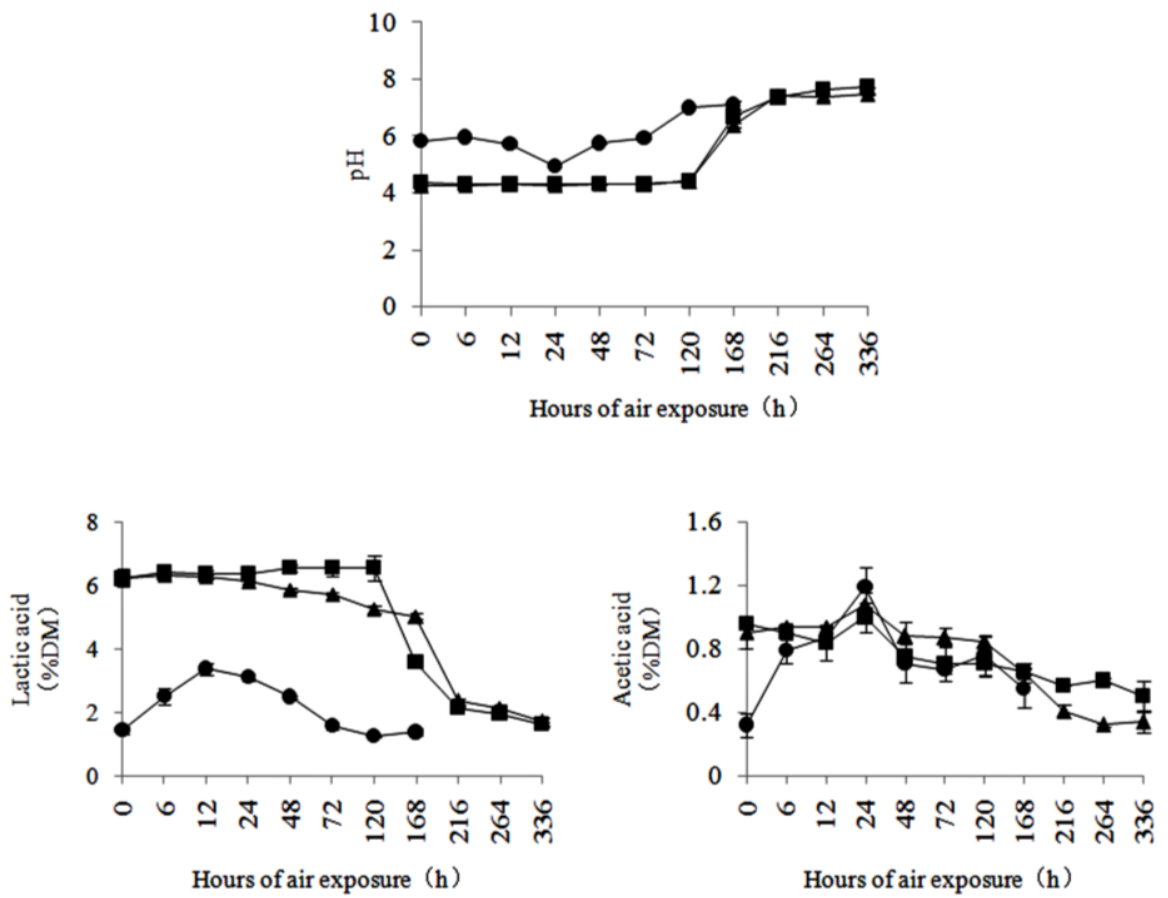

Figure 3. Microbial composition, $\mathrm{pH}$ and organic acids of LTMR and LTMR silage in the processing of aerobic deterioration. TMR were marked by $\bullet$, TMR silages after $28 \mathrm{~d}$ of ensiling were marked by $\boldsymbol{\bullet}$, and TMR silages after $56 \mathrm{~d}$ of ensiling were marked by $\boldsymbol{\Delta}$. LTMR, total mixed ration with Leymus chinensis hay; TMR, total mixed ration.

during the middle stage of aerobic deterioration and became dominant. In 56-d TMR silages, L. buchneri constituted the majority of LAB. Overall, L. buchneri could be observed in TMR before ensiling and in TMR silages subjected to aerobic deterioration, which is consistent with the results of Wang and Nishino (2013).

In addition to L. buchneri, it is worth noting that $P$. acidilactici was also predominant during ensiling and aerobic deterioration in TMR silages. $P$. acidilactici is a common $\mathrm{LAB}$ found on plants. In recent years, the pediocin produced by $P$. acidilactici has received widespread attention, and Pediococcus species are often used to preserve foods and feeds and can be utilized as probiotics. Gonzalez and Kunka (1987) reported that P. acidilactici PAC 1.0 showed activity against different strains of $P$. acidilactici, P. pentosaceus, L. plantarum, L. casei, L.

Table 3. The composition of dominant lactic acid bacteria at different fermentation time of ATMR silages and LTMR silage

\begin{tabular}{lcl}
\hline Treatment & Days & Lactic acid bacteria \\
\hline ATMR & $0,1,3,7$ & Pediococcus pentosaceus, Lactobacillus plantarum, Weissella paramesenteroides \\
& 14,28 & Pediococcus acidilactici, Lactobicillus brevis, Lactobacillus plantarum \\
LTMR & 56 & Pediococcus acidilactici, Lactobacillus buchneri \\
& $0,1,3,7,14$ & Pediococcus pentosaceus, Pediococcus acidilactici, Lactobicillus brevis \\
& 56 & Pediococcus acidilactici, Lactobicillus brevis \\
\hline
\end{tabular}

ATMR, total mixed ration with alfalfa hay; LTMR, total mixed ration with Leymus chinensis hay. 
Table 4. The composition of dominant lactic acid bacteria at different time of aerobic deterioration in ATMR, LTMR, ATMR silages and LTMR silage

\begin{tabular}{|c|c|c|}
\hline Treatment & Hours & Lactic acid bacteria \\
\hline \multirow[t]{2}{*}{ ATMR } & $0,6,12,24$ & Pediococcus pentosaceus, Lactobicillus plantarum, Weissella paramesenteroides \\
\hline & $48,72,120,168$ & Pediococcus pentosaceus, Lactobicillus plantarum \\
\hline \multirow[t]{3}{*}{ LTMR } & $0,6,12$ & Pediococcus pentosaceus, Pediococcus acidilactici, Lactobicillus brevis \\
\hline & $24,48,72$ & $\begin{array}{l}\text { Pediococcus pentosaceus, Pediococcus acidilactici, Lactobicillus brevis, } \\
\text { Weissella paramesenteroides }\end{array}$ \\
\hline & 120,168 & Pediococcus pentosaceus, Lactobicillus brevis \\
\hline \multirow[t]{3}{*}{$28 \mathrm{~d}$ ATMR silage } & $0,6,12,24,48,72,120$ & Pediococcus acidilactici, Lactobicillus brevis, Lactobicillus plantarum \\
\hline & 168 & Pediococcus acidilactici, Lactobacillus buchneri, Lactobicillus plantarum \\
\hline & $216,264,336$ & Pediococcus acidilactici, Lactobacillus buchneri \\
\hline \multirow[t]{3}{*}{28 d LTMR silage } & $0,6,12,24,48,72$ & Pediococcus acidilactici, Lactobicillus brevis \\
\hline & 120,168 & Pediococcus acidilactici, Lactobacillus buchneri, Weissella paramesenteroides \\
\hline & $216,264,336$ & Pediococcus acidilactici, Lactobacillus buchneri \\
\hline \multirow[t]{2}{*}{$56 \mathrm{~d}$ ATMR silage } & $0,6,12,24,48,72,120,168$ & Lactobacillus buchneri, Pediococcus acidilactici \\
\hline & $216,264,336$ & Lactobacillus buchneri, Pediococcus acidilactici, Weissella paramesenteroides \\
\hline \multirow[t]{3}{*}{56 d LTMR silage } & $0,6,12,24,48,72$ & Lactobacillus buchneri, Pediococcus acidilactici \\
\hline & 120,168 & Lactobacillus buchneri, Pediococcus acidilactici, Weissella paramesenteroides \\
\hline & $216,264,336$ & Lactobacillus buchnerii, Weissella paramesenteroides \\
\hline
\end{tabular}

ATMR, total mixed ration with alfalfa hay; LTMR, total mixed ration with Leymus chinensis hay.

bifermentans, and Leuconostoc mesenteroides subsp. dextranicum. Digaitiene (2012) isolated P. acidilactici KTU05-7 from rye sourdoughs, and this strain showed antibacterial activity against other LAB. Furthermore, $P$. acidilactici KTU05-7 produced bacteriocin-like inhibitory substances unlike any other known bacteriocins, which were shown to have good antimicrobial activity against Bacillus subtilis and some fungi. Mandal (2013) also reported that $P$. acidilactici LAB5 can inhibit the growth of many food-spoilage fungi, and this wide inhibitory spectrum against food-spoilage and plant-pathogenic fungi enriched its applicability in food preservation. In this study, $P$. acidilactici and L. buchneri were the predominant LAB in the later stage of ensiling and during aerobic deterioration of TMR silages. $P$. acidilactici might produce bacteriocin during ensiling that inhibits certain LAB and other harmful microorganisms, and this bacteriocin can be effective during aerobic deterioration. Most previous studies have focused on the inhibition of yeast and harmful bacteria by organic acids and ignored the antagonism between microorganisms caused by bacteriocins. In future research, the roles of $P$. acidilactici in the ensiling process and aerobic stability are worth examining.

\section{CONCLUSION}

The data presented here confirm that peach pomace can be utilized effectively by incorporating it into TMR silages. The TMR silages with peach pomace showed good fermentation quality, nutritional value, and aerobic stability. Yeast populations at silo opening had a marginal effect on aerobic stability. Although marked changes were seen in the LAB community during ensiling and aerobic deterioration, L. buchneri and P. acidilactici may play a major role in the aerobic stability, and further study is necessary to evaluate the effect of $P$. acidilactici.

\section{ACKNOWLEDGMENTS}

Financial support for this research was provided by National Natural Science Foundation of China (31172240) and special fund for Agro-scientific Research in the Public Interest (201003023, 201303061).

\section{REFERENCES}

AOAC. 1990. Official Methods of Analysis. 15th ed. Association of Official Analytical Chemists, Arlington, VA, USA.

Adil, I. H., H. I. Çetin, M. E. Yener, and A. Bayindirli. 2007. Subcritical (carbon dioxide + ethanol) extraction of polyphenols from apple and peach pomaces, and determination of the antioxidant activities of the extracts. J. Supercrit. Fluids 43:55-63.

Abdollahzadeh, F., R. Pirmohammadi, F. Fatehi, and I. Bernousi. 2010. The effect of feeding ensiled mixed tomato and apple pomace on performance of Holstein dairy cows. Slovak. J. Anim. Sci. 1:31-35.

Cao, Y., T. Takahashi, and K. Horiguchi. 2009. Effects of addition of food by-products on the fermentation quality of a total mixed ration with whole crop rice and its digestibility, preference, and rumen fermentation in sheep. Anim. Feed Sci. Technol. 151:1-11.

Digaitiene, A., A. S. Hansen, G. Juodeikiene, D. Eidukonyte, and J. Josephsen. 2012. Lactic acid bacteria isolated from rye 
sourdoughs produce bacteriocin-like inhibitory substances active against Bacillus subtilis and fungi. J. Appl. Microbiol. 112:732-742.

Faravash, R. S. and F. Z. Ashtiani. 2008. The influence of acid volume, ethanol-to-extract ratio and acid-washing time on the yield of pectic substances extraction from peach pomace. Food Hydrocoll. 22:196-202.

Gonzalez, C. F. and B. S. Kunka. 1987. Plasmid-Associated bacteriocin production and sucrose fermentation in Pediococcus acidilacticl. Appl. Environ. Microbiol. 53:25342538.

Gao, L., H. Yang, X. Wang, Z. Huang, M. Ishii, Y. Igarashi, and Z. Cui. 2008. Rice straw fermentation using lactic acid bacteria. Bioresour. Technol. 99:2742-2748.

Kim, W. K., W. Mauthe, G. Hausner, and G. Klassen. 1990. Isolation of high molecular weight DNA and double-stranded RNAs from fungi. Can. J. Bot. 68:1898-1902.

McDonald, P., A. R. Henderson, and S. J. E. Heron 1991. The Biochemistry of Silage, 2nd ed. Chalcombe Publ., Cambrian Prrinters, Ltd., Merlow, Bucks, Aberystwyth, Wales, UK.

Mandal, V., S. K. Sen, and N. C. Mandal. 2013. Production and partial characterization of an inducer-dependent novel antifungal compound(s) by pediococcus acidilactici LAB 5 . J. Sci. Food Agric. 93:2445-2453.

Muck, R. E. 2013. Recent advances in silage microbiology. Agric. Food Sci. 22:3-15.

Nishino, N., H. Wade, M. Yoshida, and H. Shiota. 2004. Microbial counts, fermentation products, and aerobic stability of whole crop corn and a total mixed ration ensiled with and without inoculation of Lactobacillus casei or Lactobacillus buchneri. J. Dairy Sci. 87:2563-2570.

Nishino, N. and H. Hattori. 2007. Resistance to aerobic deterioration of total mixed ration silage inoculated with and without homofermentative or heterofermentative lactic acid bacteria. J. Sci. Food Agric. 87:2420-2426.

Pahlow, G., R. E. Muck, F. Driehuis, S. J. W. H. Oude Elferink, and S. F. Spoelstre. 2003. Microbiology of ensiling. In: Silage Science and Technology (Eds. D. R. Buxton, R. E. Muck, and J. H. Harrison). American Society of Agronomy, Crop Science Society of America, Soil Society of America, Madison, WI, USA. pp. 31-93.
Simone, C. and G. Edgard. 2011. Protein extraction from biomass in bioethanol refinery-Possible dietary application: Use as animal feed and potential extension to human consumption. Bioresour. Technol. 102:427-436.

Van Soest, P. J., J. B. Robertson, and B. A. Lewis. 1991. Methods for dietary fiber, neutral detergent fiber, and non-starch polysaccharides in relation to animal nutrition. J. Dairy Sci. 74:3583-3597.

Wang, C. and N. Nishino. 2013. Effects of storage temperature and ensiling period on fermentation products, aerobic stability and microbial communities of total mixed ration silage. J. Appl. Microbiol. 114:1687-1695.

Wang, F. and N. Nishino 2008. Resistance to aerobic deterioration of total mixed ration silage: Effect of ration formulation, air infiltration and storage period on fermentation characteristics and aerobic stability. J. Sci. Food Agric. 88:133-140.

Wang, F. and N. Nishino. 2009. Association of Lactobacillus buchneri with aerobic stability of total mixed ration containing wet brewers grains preserved as a silage. Anim. Feed Sci. Technol. 149:265-274.

Wang, R. R., H. L. Wang, X. Liu, and C. C. Xu. 2011. Effects of different additives on fermentation characteristics and protein degradation of green tea grounds silage. Asian Australas. J. Anim. Sci. 24:616-622.

Xu, C. C., Y. Cai, J. G. Zhang, and M. Ogawa. 2007a. Fermentation quality and nutritive value of a total mixed ration silage containing coffee grounds at ten or twenty percent of dry matter. J. Anim. Sci. 85:1024-1029.

Xu, C., Y. Cai, N. Moriya, and M. Ogawa. 2007b. Nutritive value for ruminants of green tea grounds as a replacement of brewers' grains in totally mixed ration silage. Anim. Feed Sci. Technol. 138:228-238.

Xu, C., Y. Cai, J. Zhang, and H. Matsuyama. 2010. Feeding value of total mixed ration silage with spent mushroom substrate. Anim. Sci. J. 81:194-198.

Yang, J., Y. Cao, Y. Cai, and F. Terada. 2010. Natural populations of lactic acid bacteria isolated from vegetable residues and silage fermentation. J. Dairy Sci. 93:3136-3145. 